\title{
81
}

\section{Computers, telecommunications and Western culture}

\author{
Barton D. Thurber, $P h D$ \\ Jack W. Pope, PhD \\ University of San Diego \\ United States of America \\ Jerry Stratton \\ FireBlade Publications \\ San Diego \\ United States of America
}

\begin{abstract}
Personal computers and the individualistic design of international computer networks are founded in Western concepts of democracy, interpersonal communication and freedom.. Nonwestern countries which wish to maintain cultural autonomy while importing Western technology and providing their citizens with access to international networks, will need to provide this technology and access in culturally familiar forms. The development of user interface technology which masks the inherent Western-ness of computer networks is necessary if the technology is to be integrated into a nonwestern culture rather than integrating the culture into the technology.
\end{abstract}

Main conference themes: national policies

Educational areas:

Study topics:

Secondary keywords: communication, culture, networks, telecommunications 


\title{
INTRODUCTION
}

In the course of his examination of what he thinks are imperilled Western values, Lawrence Cahoone, in The Dilemma of Modernity: Philosophy, Culture and Anti-Culture, takes a moment to define what he means by 'democratic culture':

\begin{abstract}
"What is a democratic culture? It is, first of all, a culture in which the belief in the ultimate value of the human individual, the belief that individuals are the ultimate sources of truth, value and political authority, is a dominant and pervasive cultural theme. It is a culture in which plurality, diversity, and creation of new cultural themes and traditions are not only tolerated but encouraged. It is a culture which places the highest premium on the creativity of individuals and groups. These tendencies would seem centripetal and anarchic, except that democratic culture is above all a culture of communication. Democracy stakes its existence on the conviction that open, free and never-ending discussion can bring together its disparate cultural elements, not in agreement, but simply in the act of communication between equally free citizens."[1]
\end{abstract}

A few years later Adam Gaffin, as if having internalized, if not Cahoone's description then any of thousands like it, would maintain in his preface to the Big Dummy's Guide to the Internet that

"Digital communications media are inherently capable of being more interactive, more participatory, more egalitarian, more decentralized, and less hierarchical. As such, the types of social relations and communities which can be built on these media share these characteristics..."

The new forums atop computer networks are the great levellers and reducers of organizational hierarchy. Each user has, at least in theory, access to every other user, and an equal chance to be heard. Computer networks do not require tightly centralized administrative control. In fact, decentralization is necessary to enable rapid growth of the network itself. The explosion of Gopher sites on the Internet was a result of Gopher encouraging distribution of servers. Given these characteristics, networks hold tremendous potential to enrich our collective cultural, political and social lives and enhance democratic values everywhere [2].

Gaffin is clearly describing the electronic incarnation of values Cahoone (and countless others) have ascribed to the Western liberal democratic tradition. Both are themselves Westerners, writing from within a context they both describe and, not surprisingly, endorse. And both, we want to argue, typify the 
characteristically Western thinking which has led to the creation of, and later to the particular structure of, the Internet, as well as to the development of certain kinds of software and probably even to the development of the hardware, the computer. For the time being our goal is not so much to criticize this development as simply to notice it; and, assuming that our proposition is correct, to think practically about what might be done in response. Is it necessary to westernize in order to computerize?

\section{The Western computer}

That computer networks embody liberal Western ideas about freedom and democracy has been remarked before, at least in passing. In their discussion of business networking strategies Lee Sproull and Sara Kiesler notice [3] that "new communication technology is surprisingly consistent with Western images of democracy"; Howard Rheingold [4] quotes a young Japanese telecommunications pioneer, Joichi Ito, to the effect that "You'll see a reaction coming, a kind of allergic reaction" to the Internet, because it is so Western-and, indeed, Takashi Kiuchi, chairman of Mitsubishi Electric America Inc., has gone so far as to say that "The information highway is so tied to American culture that we can't even understand what we're getting into."[5] Note that all three react not to the content conveyed by electronic media so much as to the nature of computerized telecommunication itself. That the content conveyed by electronic media has a Western bias has long been clear, but that the nature and structure of electronic telecommunication might itself be Western is a relatively new proposition.

Moreover, what seems Western about developing computer networks - their noncentrality, their resistance to hierarchical organization and/or decision making, their capacity to empower all users equally-applies not only to computer networks, but to computers themselves, particularly personal computers. That personal computers and smaller servers have tended to replace mainframes is no accident, in cultural terms; as we have argued before [6] by concentrating computing power at the point of the individual, rather than the organization, the $\mathrm{PC}$, and particularly the demonstrated preference for PC's at the expense of larger machines, mirrors a characteristically Western political and cultural emphasis on individual freedom.

Moreover, the hypermedia model for information retrieval is now global as well as local, thanks to technology such as Gopher and World Wide Web. Except for access time and external factors, such as whether a particular machine or gateway is up or not, there is now no perceptual or cognitive difference between hypermedia accessed/created on one's own PC and hypermedia accessed/created on the Net. This means, for example, that any culture which might want to restrict or otherwise govern the flow of 
information towards it - in self defence, if for no other reason-faces the triple problem of exposure to the Net, exposure to hypermedia and exposure to the computer itself - all of which are, in the developing global cyberspace, inseparable. But the technology is not transparent; the specific freedoms it embodies are idealized versions of generically Western freedoms; and any nonwestern culture which undertakes computerization, much less networked electronic communication, should understand that in doing so it may be importing, willy-nilly, values alien to its own. (It may also be importing values not alien to its own. Our point is just that importing the technology is importing values.)

Two caveats before we proceed. First, we do not mean to imply that Western (or any) culture can be summed up in a few sentences, as we have just done. It is true that something like what Cahoone and Gaffin naively take to be 'democratic', has accompanied aspects of Western culture, as discussions (for example) as various as Franz Borkenau's analyzis of the differences between Eastern and Western monasticism [7] or Herbert Muller's meditation on the democratizing impact of the Reformation [8] make clear. On the other hand, 'culture', 'democracy' and 'freedom' are all such polyvalent concepts that to do anything more than sketch what we mean by 'Western' ideas about those concepts scarcely seems feasible. Our goal is to be suggestive rather than final.

Second, it has often seemed, particularly in the West, that computers and computerized telecommunications deconstruct values of all kinds, including Western ones. Jacques Ellul claims [9] of all modern technology that

"We see the concept of democracy called into question by the manipulation of the media, the falsification of political discourse and the establishment of a political class which, in all countries where it is found, simply negates democracy."

Meanwhile, the very subtitle of George Landow's Hypertext ('The Convergence of Contemporary Critical Theory and Technology') underscores his contention that computer based hypertext reifies much contemporary (Western) literary and philosophical debate - "deconstructing" authors, reading, texts themselves, so that the possibility of mere cultural bias tends to disappear [10].

We think Ellul is just wrong, particularly where computers are concerned. As regards contemporary literary theory, we would argue that it is itself crucially and characteristically Western; the Derridaian project-to disassemble authors' intentionality, meaning itself if meaning is an a priori deposit left by the author-is part of the same individualizing, democratizing, disassembling impulse which led as well to the creation of hypertext or, for that matter, to the development of Western liberal democracies. Landow himself recognized this; 
he quotes with approval J. Hillis Miller's assertion that "the new regime of telecommunications seems to be inherently democratic. It has helped (in 1989) bring down dictator after dictator in the past few months." [10, p. 179]

That Miller opposes 'democracy' and 'dictators' is instructive, and betrays what has been a related kind of cultural bias in discussions about telecommunications; 'dictatorship' in various forms is imagined to be the result if electronic 'freedom' is constrained. The possibility that 'freedom' might be redefined, or that other differences—not oppositions-might be possible, has been ignored.

\section{What to Do}

Our first suggestions regarding what might be done, apply to nonwestern cultures confronting Western telecommunications technologies. Afterwards we will have something to say to Westerners.

The first hurdle to be met by nonwestern cultures will be the computer itself. By the sheer fact of its interactivity, the freedom it grants users to alter pre-existing texts or documents, it embodies Western ideas about what freedom is and what it feels like. You occupy the same electronic space occupied by the originators, you manipulate text and symbol on the same keyboard, you are enabled in the way heretofore remote originators have been. For cultures less tied to individualism than the West, or more interested in preserving a heritage, this in itself can be a formidable problem and is the beginning of what we mean when we say that in cultural terms technology is value.

Computers are expensive and they are technological, of course, which imply other things about the culture which successfully uses them. It will need some kind of technological base and it will need money.

But there are also other, more abstract ways in which the computer enforces a Western tilt. Electronic communication itself is abstract in the sense that it is not immediately personal; no one sees or expects to see (or smell, or touch) another person on the Net, but in many cultures communication cannot be said to exist unless those conditions are satisfied. Moreover, the keyboard tends to favour languages (and cultures) whose language is alphabetical and phonetic, as Western languages are; but the Japanese, Chinese and others have discovered that this can be a major problem in actually using the machine. Further technological developments (voice and optical character recognition technology) may ease the problem - and, in fact, this would be our first advice to any nonwestern culture which can afford it: "As it exists now the computer is a Western cultural artefact. Change the computer to change the culture." Look at alternative technologies for user interface equipment such as the keyboard. Consider alternative network models: a centralized system might have a better chance of preserving traditional values than a distributed one. 
Produce as many electronic documents as possible in as many indigenous languages as possible, particularly where international communication networks are involved. Look at innovative ways to combine abstract and impersonal electronic forms of communication with concrete, interpersonal ones. Virtual world software, even text based ones such as $M O O$, might be used to mould the interface to the culture.

Hypermedia present different problems. If, as we have suggested, hypermedia embody Western values aside from what they may actually be about, then a culture which decides to use hypermedia is deciding, at some level, to be Western. There are cultures which want to do this; for those which do not, the fact that hypermedia are available both locally and globally on the Net makes a serious problem truly formidable.

Our first response is a pessimistic one. The prospect of remedying the situation is daunting in the absence, thus far, of any alternative; and the development of alternatives will depend upon the Western technology which has created the problem! Our conclusion is that it is currently not possible to avoid a Western bias completely. Nonwestern cultures should be aware of this fact in planning telecommunications policy.

On the other hand, if complete isolation from Western values is not possible, greater cultural electronic autonomy is. Policy makers may wish to limit the nature and quantity of electronic information flowing into and out of their region or country. While censorship as such presents a number of practical as well as (in some cultures) legal/ethical problems, it probably is possible to choose which gates to open and which to close-for reasons, to be clear, which have nothing necessarily to do with 'dictatorship', but much to do with cultural and political hegemony. (This is a concern even to some Western countries: France continues to wage a war against the franglicization of its culture. Enhancing net access to reflect a specific culture-whether it means providing native language translations of high traffic items or culturally familiar virtual worlds - is certainly preferable to providing raw access to an unfamiliar world.)

Second, the language of international telecommunications is a Western language-English; policymakers should foster electronic communications in indigenous languages, using indigenous sounds and images, whenever possible. English is necessary in order to communicate internationally on the Net; it is not necessary for a nonwestern culture's own dialogue with itself.

We would also suggest that nonwestern cultures interested in limiting the extent to which they are westernized, produce, not simply their own electronic documents, but their own kinds of documents. Hypermedia are the rhetorical images of the liberal Western culture which invented them. Other rhetorical images must be possible, as there are other cultures and other languages, if not, 
yet, other technologies. As Westerners ourselves we are limited in imagining what these other documents might be like; in an important sense we do not want to, since any such development, which would enrich us all, would occur in nonwestern places, in nonwestern, we hope, electronic spaces.

Finally, to our Western colleagues we would urge a much greater awareness than has been shown to date of the ways in which their own most valued, most obvious and most unconscious assumptions mark them - and of the ways in which those assumptions can prevent others from being who they are. The very call for freedom itself can be, if we are correct, the call for freedom's absence; free and equal access to everything can enforce cultural and ultimately political and economic agendas. The naive idealism with which many of us have approached hypermedia and the Net should be tempered by the realization that these technologies brand us as who we are; we have no right, on our own most idealistic grounds, to brand others in the same way.

\section{REFERENCES}

1. Cahoone, L. (1988) The Dilemma of Modernity: Philosophy, Culture and Anti-Culture., State University of New York Press, Albany, New York, p. 270.

2. Gaffin, A. (1993) Big Dummy's Guide to the Internet, electronic publication of the Electronic Frontier Foundation, preface.

3. Sproull, L. and Kiesler, S. (c. 1992) Connections: New Ways of Working in the Networked Organization. MIT Press, Cambridge, p. 13.

4. Rheingold, H. (c. 1993) The Virtual Community: Homesteading on the Electronic Frontier. Addison-Wesley, pp. 218-219.

5. Armstrong, L. and Holyoke, L. (1994) Look Who's Stuck in the Slow Lane. Business Week, March 28, 1994, p. 28.

6. Thurber, B.D. and Pope, J.W. (1990) Von Neumann's Legacy: Technology and Freedom, in WCCE/90 Fifth World Conference on Computers in Education Conference Abstracts, Sydney, Australia.

7. Borkenau, F. (1981) End and Beginning: On the Generations of Cultures and the Origins of the West. Columbia University Press, New York, pp. 339340 . 
8. Muller, H.J. (c. 1963) Freedom in the Western World: From the Dark Ages to the Rise of Democracy. Harper \& Row, New York, pp. 96-101.

9 Ellul, J. (c. 1992) Technology and Democracy, in Democracy in a Technological Society, (ed. Langdon Winner), Kluwer Academic Publishers, Dordrecht/Boston/London, p. 35.

10. Landow, G.P. (c. 1992) Hypertext: The Convergence of Contemporary Critical Theory and Technology. The Johns Hopkins University Press, Baltimore and London. 